\title{
Laços Desfeitos: Os dramas familiares em Lygia Fagundes Telles e Lya Luft
}

\author{
Broken Ties: Family dramas in Lygia Fagundes Telles and Lya Luft
}

Urandi Rosa Novais ${ }^{1}$

\begin{abstract}
RESUMO: Este artigo se propõe a realizar uma análise interpretativa, traçando um estudo comparativo da representação da família na produção literária das escritoras Lygia Fagundes Telles e Lya Luft. Nosso objetivo foi investigar como as personagens lidam com os mais diversos temas que cercam a família na qual estão inseridas como, por exemplo, os padrões impostos pela sociedade, a decadência de valores, a traição e a morte. Trata-se uma pesquisa bibliográfica de caráter analítico e interpretativo, cujo corpus foi composto por um conto, "O espartilho", de Lygia Fagundes Telles (2010); e o romance $A$ asa esquerda do anjo, de Lya Luft (2004). As ideias e discussões apresentadas estão baseadas em teóricos e críticos como Bachelard (1989), Beauvoir (2016), Chevalier (2012), Xavier (2017) e Lucena (2013, 2015), entre outros, que nos possibilitaram entender o quanto a temática da família é instigante nas obras dessas autoras, abrindo-nos um leque de possibilidades de estudos.
\end{abstract}

PALAVRAS-CHAVES: Lygia Fagundes Telles; Lya Luft; Dramas Familiares; Família; Memória.

ABSTRACT: This article proposes to perform an interpretative analysis, tracing a comparative study of the representation of the family in the literary production of the writers Lygia Fagundes Telles and Lya Luft. Our objective was to investigate how the characters deal with the most diverse issues surrounding the family in which they are inserted, such as the standards imposed by society, the decay of values, betrayal and death. It is a bibliographical research of analytical and interpretative character, whose corpus was composed by a short story, "O Espartilho" (2010), by Lygia Fagundes Telles; and the novel, A Asa Esquerda do Anjo (2004), by Lya Luft. The ideas and discussions presented are based on theoreticians and critics such as Bachelard (1989), Beauvoir (2016), Chevalier (2012), Xavier (2017) and Lucena (2013, 2015) among others, which enabled us to understand how much the theme of the family is intriguing in the works of these authors, opening a wide range of study possibilities.

KEY-WORDS: Lygia Fagundes Telles; Lya Luft; Family dramas; Family; Memory.

O presente ensaio apresenta uma análise interpretativa acerca da representação da família na produção literária de Lygia Fagundes Telles e Lya Luft. Para esse trabalho foram escolhidos o conto $O$ espartilho, de Lygia Fagundes Telles e o romance $A$ asa esquerda do anjo, de Lya Luft. Interessa-nos como as relações familiares são construídas e como as personagens lidam com os dramas que as circundam como, por exemplo, os padrões impostos, a decadência de valores, a traição e a morte. Os textos ficcionais se inserem na escrita de autoria feminina, compreendidos na segunda fase e que representa a fase de protesto e quebra dos padrões (XAVIER, 1999) ${ }^{2}$. Os

\footnotetext{
${ }^{1}$ Mestre pelo PROGEL, Programa de Estudos Literários, da UEFS, Universidade Estadual de Feira de Santana. É Professor de Língua Portuguesa e Produção Textual na FTC, Faculdade de Tecnologia e Ciências, Campus Comércio. E-mail: urandinovais@gmail.com.

${ }^{1}$ No ensaio $A$ narrativa de autoria feminina na literatura brasileira: marcas da trajetória, Elódia Xavier apresenta três etapas que compreendem a escrita de autoria feminina. A primeira é a feminina, compreendida entre 1840 até 1960, tendo a cultura dominante como referencial, ou seja, modelos da tradição são reproduzidos. A segunda, a feminista, que é
} 
personagens abordados são mulheres que, na tentativa de entender suas origens, buscam quebrar determinadas regras sociais, com o intuito de colocar em xeque alguns padrões impostos por uma sociedade patriarcal em decadência.

As narrativas apresentam personagens que estão presas a um contexto familiar, onde a opressão e a hipocrisia mascaram o que há por trás das famílias. No conto "O Espartilho”, a protagonista Ana Luísa busca a real origem de sua mãe, enquanto sofre com a descoberta de que aquela a quem mais admirava, a avó, na verdade não passava de uma imagem falsa, e dela tenta se livrar para não mais sofrer com o modelo de educação que ela a obrigava seguir. No romance $A$ asa esquerda do anjo, Gisela busca, através da memória, entender o fracasso de sua família e o porquê nuca fora aceita por sua avó, a matriarca Frau Wolf que a martirizava e a todos os demais membros da família.

Podemos afirmar que tanto a protagonista de Lygia Fagundes Telles quanto a de Lya Luft são colocadas numa espécie de jogo, onde solidão, desespero, traição, hipocrisia e opressão estão presentes em todas as jogadas, fazendo-as fracassar, pois não conseguem sair vitoriosas do labirinto da vida. Elas são sufocadas pela ironia do destino, o castigo da memória e a ação da morte.

\section{OPRESSÃO E HIPOCRISIA EM O ESPARTILHO}

O conto, O espartilho, é narrado em primeira pessoa, pela protagonista da história, Ana Luísa que busca entender sua origem, na busca por sua identidade no seio da família Rodrigues. A história se desenrola a partir das lembranças da narradora, principalmente em relação a um antigo álbum que sua avó a apresentava, narrando as grandiosidades da família, num tom enaltecedor, pois para a matriarca da família, cada parente era venerado, quase santificado.

A narradora é órfã e foi criada pela avó, desde pequena, como narra em uma de suas memórias: "a primeira imagem que tenho de mim mesma é a de uma menininha de avental azul, instalada na almofada de veludo na sala de visitas com um vago cheiro de altar. Ao lado de minha avó com sua sacola de tricô" (TELLES, 2010, p. 31). A imagem da avó, no primeiro momento, é vista pela menina como representante da sabedoria, que a ensinaria a ser uma pessoa edificada, como os demais parentes, como podemos perceber na seguinte passagem da narrativa:

Tudo era harmonioso, sólido e verdadeiro. No princípio. As mulheres, principalmente as mortas do álbum, eram maravilhosas. Os homens, mais maravilhosos ainda, ah, difícil encontrar família mais perfeita. A nossa família,

uma espécie de ruptura dos modelos tradicionais, uma fase de protestos, valorização das minorias e luta por direitos. Por último, a fase fêmea que é a autodescoberta, a busca por uma identidade. Vale ressaltar que uma mesma escritora pode produzir obras pertencentes a diferentes fases. 
dizia a bela voz de contralto da minha avó. Não havia o medo. No principio. E por que o medo? Casa do vizinho podia ter sido edificada sobre a areia mas a nossa estava em terra firmíssima, acentuava minha avó. Ela gostava das citações bíblicas (TELLES, 2010, p. 31).

Em seu estudo sobre a infância nos contos de Lygia Fagundes Telles, Rosa Maria de Carvalho Gens (2008) considera a narrativa de $O$ Espartilho sob a vertente da educação recebida pela mulher na família. Pois é perceptível que a menina busca todo momento seguir os ensinamentos da avó, sem questioná-los, e tem como dogmas as histórias que a matriarca narra sobre cada familiar que está representado no álbum da família. No entanto, ao passar do tempo a menina percebe que o modelo de educação ao qual está sendo submetida pela matriarca é perverso e não passa de uma farsa.

O próprio título do conto já nos permite uma leitura metafórica de seu enredo. O espartilho é uma peça feminina usada para modelar a silhueta, escondendo as imperfeições do corpo. No conto em questão, ele representa o discurso mascarador que a matriarca utiliza para esconder os podres da família, fazendo com que sua neta a idolatre como fonte de sabedoria e portadora da verdade única e absoluta. Além do mais, a avó, com seu discurso dissimulado, quer que Ana Luisa acredite que sua família é perfeita e superior a toadas as outras.

Os conflitos de Ana Luísa começam quando Margarida ${ }^{3}$, uma agregada da família, conta todas as histórias macabras que estão por trás das falsas histórias daquelas belas pessoas que compõem o álbum da família. A agregada não poupa a protagonista de nenhuma das atrocidades que estão por trás da família Rodrigues: o golpe do baú que o tio Maximiliano deu numa inglesa; a tia Consuelo que enlouquecera por falta de homem, e acabou sendo trancafiada num convento, para não macular o nome da família; e o mais escabroso de todos foi revelar que a mãe de Ana Luísa era judia.

A partir dessas revelações, Ana Luísa começa a questionar sua origem e revirar na memória todas as possíveis lembranças de sua mãe, com o intuito de estabelecer características entre sua genitora e os judeus: "Sobre minha mãe as referências eram rápidas. Superficiais. Sob qualquer pretexto evocava-se a figura do meu pai com sua inteligência, seu humor. Eu não sabia o que era humor, mas se isso fazia parte do meu pai, devia ser uma qualidade. E minha mãe? Por que continuava isolada no seu cone de silêncio?” (TELLES, 2010, p. 35-36).

\footnotetext{
2 Margarida é filha de Isaura e Neta de Ifigênia, primeira agregada da família de que se tem notícia na narrativa. "Falou também sobre suas origens, ah, não tinha ilusões. Falou na avó, na preta Ifigênia. Desde mocinha Ifigênia engomava a roupa da família, o ferro atochado de brasas, era a idade da goma. As camisas lustrosas. As saias lustrosas, duras. Quando ela engravidou, o tio Maximiliano foi mandado às pressas para a Europa, todos sabiam. E ninguém sabia nada. Com a mesma pressa com que embarcou foi providenciado para ela um casamento. O escolhido era um agregado da família (tantos agregados!) que era sargento e gostava de tocar violão" (TELLES, 2010, p. 36).
} 
No entanto, como sua memória não se mostra capaz de solucionar os dilemas e enigmas que cercam a identidade de sua mãe, Ana Luísa recorre à memória alheia que, nesse caso é o álbum da família, e também alguns elementos de conversas existentes entre sua avó a as amigas, durante as tardes de caridade que sua avó organizava para receber as amigas. Segundo Halbwachs apud Camargo e Filho (2013, p. 183) "Recorremos a testemunhos para reforçar ou enfraquecer e também para completar o que sabemos de um evento sobre o qual já temos alguma informação, embora muitas circunstâncias a ele relativas permaneçam obscuras para nós". E desta forma, juntando as pistas: poucas referências sobre sua mãe, a ausência de fotografias delas no consagrado álbum da família Rodrigues fez Ana Luísa perceber sua real descendência.

Convém lembrar que o conto em questão se passa no período em que Hitler perseguia os judeus na Alemanha. Então, para a família de Ana Luísa, descendente de alemães, ter uma judia na família era uma afronta, motivo de vergonha. Por isso, a matriarca buscava ocultar essa verdade da neta, como também formá-la num modelo que realçasse apenas as características do genitor, ou seja, de um descendente alemão.

Ao constatar que os podres outrora contados por Margarida eram as reais histórias que envolviam sua família, a protagonista perde todo o encanto por sua avó, esta que antes era vista como sabedoria e porto seguro, agora se torna alguém de quem Ana Luísa queria se ver livre, pois percebeu a hipocrisia e a opressão que estavam por trás do discurso de sua avó. Uma das tentativas foi tentar se casar, pois se veria livre da matriarca, no entanto seria submissa aos mandos e desmandos do futuro marido, como mostra o seguinte trecho da narrativa:

\footnotetext{
E se me casasse? Seria uma forma de me libertar, mas no lugar da avó ficaria o marido. Teria então que me livrar dele. A não ser que o amasse. Mas era muito raro os dois combinarem em tudo. Advertiria minha avó... Ia começar a batalha do casamento. Batalha? Nome demais pomposo, não haveria nenhuma batalha, eu devia apenas me casar cedo, destino natural das jovens assim obscuras. E sem ambição. Não quero fechar os olhos antes de deixá-la em segurança, costumava dizer. E segurança era ter um marido. $\mathrm{O}$ risinho vinha em seguida, quando perversamente se referia às minhas tias solteiras, essas encalhadas (TELLES, 2010, pp. 54-6).
}

Pela passagem da narrativa, mesmo tentando escapar das artimanhas de sua avó, a Ana Luisa resta apenas um casamento, ou seja, submeter-se a um padrão imposto pela sociedade da época, como afirma Beauvoir (2016, p. 186): “o destino que a sociedade propõe tradicionalmente à mulher é o casamento. Em sua maioria, ainda hoje, as mulheres são casadas, ou o foram, ou se preparam para sê-lo, ou sofrem por não sê-lo”. E essa preparação para o casamento é perceptível ao longo de toda a narrativa, pois mesmo vivendo o drama de saber sua real origem, a 
protagonista era formada para ser uma boa dona de casa, aprendendo a recitar, entender de roupas, organização da casa, ser delicada, ou seja, tornar-se apta para ser a rainha do lar.

No entanto, Ana Luisa conhece Rodrigo ${ }^{4}$ na saída da igreja e com ele vive uma paixão avassaladora. Ao fazer isso, ela transgride alguns dos padrões de sua época, pois num contexto em que as moças deveriam preservar sua virgindade para o casamento, como pregava sua avó: "Virgindade. As jovens se dividiam em dois grupos, o das virgens e o grupo daquelas que não eram mais virgens ... - uma agressão à família” (TELLES, 2010, p. 54). Ela subverte essa tradição e se deixa levar pelos desejos de conhecer e viver a sexualidade, recebendo e proporcionando prazer num contexto em que a mulher devia apenas satisfazer os desejos do marido. Isso fica claro na seguinte passagem da narrativa:

Na semana seguinte já estávamos nus debaixo de sua manta de lã, ouvindo seus discos. Se houver prazer, melhor ainda, disse minha avó. Mas esse prazer é raro. Principalmente rápido, descobri e me abria inteira para fazê-lo feliz porque ele ficava feliz. Queria vê-lo esgotado, queria que seu corpo harmonioso e rijo desabasse amolecido ao lado do meu tão tenso (TELLES, 2010, p. 56).

Ao agir dessa forma, Ana Luisa reforça uma das principais características da narrativa ligiana que é refletir sobre a transição entre tradição e progresso. Essa transição na maioria das vezes resulta na deterioração de costumes, pois boa parte de suas personagens subvertem os modelos impostos, provocando diversos embates nos relacionamentos familiares. Pois, ao entregar-se a uma paixão e entregar seu corpo ao amado, Ana Luisa estava transgredindo os ensinamentos e preceitos que sua avó tanto defendia. No entanto, essa transgressão é punida, pois a avó, como a fiandeira que tece o fio da vida e projeta o destino de cada um, faz de tudo para aproximar-se do jovem com quem a neta está se envolvendo e faz de tudo para afastá-lo da neta.

Para a avó, o jovem pretendente a esposo de Ana Luisa não estava à altura da família. Era uma pessoa sem estabilidade. E preconceituosa como era, jamais permitiria que uma pessoa desse tipo entrasse na família Rodrigues. Como no jogo de xadrez que Ana Luísa sempre jogava com sua avó, agora era ela a peça a ser encurralada por aquela matriarca manipuladora e ardilosa dando o xeque mate, fazendo com que Ana Luisa, mais uma vez perdesse a batalha.

\footnotetext{
3 "Chovia. Fiquei no alto da escadaria da igreja, olhando a rua. Foi então que Rodrigo veio me oferecer o guardachuva. Você estava na missa? Perguntei e ele riu e não respondeu. Em romances e no cinema eu já tinha visto demais a fórmula fácil de dizer, que extraordinário! Tenho a impressão que já nos conhecemos há tanto tempo" (TELLES, 2010, p. 56).
} 


\section{A DEGRADAÇÃO DA FAMÍLIA EM A ASA ESQUERDA DO ANJO}

Publicado em 19815, o livro $A$ asa esquerda do anjo é narrado por uma narradorapersonagem, Gisela, que nos traz à baila a desestruturação da família Wolf, e a impossibilidade que ela tem de se ver inserida nesse laço familiar que, ao longo do romance, através das memórias narradas, vai se desfazendo. E é nesse jogo associativo entre o lembrar e o esquecer que Gisela busca recompor as jogadas do destino que levou cada um dos membros da sua família.

Todo o romance é narrado com base na memória de Gisela, e essa memória está representada a partir da imagem de uma pequena porta que havia no porão do casarão de sua avó. Esse espaço a intrigava enquanto criança, e depois de velha é essa imagem que a faz tentar recompor a sua própria história e a de sua família. E, para além da memória, não podemos dispensar o valor psicológico que o espaço da casa representa nessa narrativa. Pois, "para um estudo fenomenológico dos valores de intimidade do espaço interior, a casa é, evidentemente, um ser privilegiado; isso, é claro, desde que a consideremos ao mesmo tempo em sua unidade e complexidade" (BACHELARD, 1989, p. 24).

Dividido em seis partes, cada uma iniciada pela gestação e espera de um parto que a narradora aguarda, podemos afirmar que o romance de Lya Luft apresenta, em sua composição, os princípios da sociedade patriarcal. Esses princípios se fazem presentes na imagem da matriarca da família, a temida e manipuladora Frau Wolf. Ela é quem assume com mãos de ferro as rédeas da família, exigindo como cada um deve se comportar, interferindo na vida de todos, principalmente na de Gisela que, ao longo do romance, rememora todas as tristezas pelas quais passou e todas provocadas, na maioria das vezes, por sua avó.

Ao analisarmos a composição do nome da matriarca da família, podemos entender a simbologia da força que ela exerce sobre o monopólio da família. Segundo Cardoso (2011), o nome Frau Ursula Wolf tem a seguinte origem: Ursula (ursa menor) representa a constelação menor de mulheres que tem Wolf (lobo) como sobrenome, este traz em sua composição o símbolo de dependência de um guardião devorador (medos e traumas da infância). Além da composição do nome, algumas descrições da referida personagem só reforçam o seu papel de poder no seio da família:

\footnotetext{
${ }^{4}$ Embora tenha sido publicado originalmente em 1981, nesse trabalho foi utilizada a $12^{\mathrm{a}}$ edição, publicada pela editora Record, em 2004.
} 
Frau Wolf não suportava atrasos. Fiscalizava ela própria minhas lições de piano, devia estar esperando no alto da escada, mão apenas repousando na bengala que usava desde uma queda há muitos anos. Minha avó, "a verdadeira Frau Wolf", como gostava de dizer, morreu aos noventa anos, e até o fim sentou-se ereta na beira da poltrona. Não se permitia fraquezas - e desprezava as alheias. Penso que, talvez sem ela mesma saber, também me desprezava, pois eu era feia e sem talentos, e comigo o sangue da família Wolf deixara de ser absolutamente "puro" (LUFT, 2004, p. 12-13, aspas do original).

A descrição de Frau Wolf revela seu status de poder na família, sempre na posição superior em relação os demais que a cercam. Ela é a guardiã do clã dos Wolf, este composto por descendentes de alemães, e a matriarca a todo custo busca manter e impor os costumes e tradições a todos os membros da família. Exige que falem em alemão com ela, até mesmo a mãe da personagem Gisela, Maria da Graça, que é uma nordestina, precisa se adaptar aos costumes da família para agradar a sogra.

Os dramas de Gisela começam desde o momento em que ela relembra sua origem, pois é filha de um descendente alemão e uma nordestina ${ }^{6}$, ou seja, o sangue puro dos Wolf fora maculado, e isso era motivo de desagrado para a sua avó que a tiranizava em todos os momentos. As desavenças entre nora e sogra eram apaziguadas pelo pai de Gisela que buscava amenizar os atritos existentes entre elas, ou seja, por amá-lo ambas se suportavam e faziam o possível para mascarar uma agradável relação entre elas. Embora Gisela tenha herdado a cor de pele dos Wolf, seu comportamento não era plausível aos olhos da avó, pois além de apresentar os traços de sua mãe, não aprendia bem as lições de piano, não sabia se comportar direito, ao contrário de Anemarie ${ }^{7}$ que era a preferida da matriarca e também modelo de beleza para Gisela.

Anemarie é filha de Ernest e Helga, esta era uma mulher fraca e inquieta, que vivia tiranizada pela presença da mãe, a matriarca Frau Wolf, e por mais tentasse jamais conseguia agradá-la. A pobre Helga sofria de males da cabeça, via e ouvia coisas do outro mundo, e se não bastasse a doença que a consumava lentamente, ela ainda era violentada sexualmente pelo próprio marido. Gisela assistiu essa cena que a marcou e a aterrorizou pelo resto de sua vida, impedindo-a de querer conhecer os segredos da sexualidade.

Anemarie era a única que conseguia fazer brilhar os olhos da avó e proporcionar-lhe alegria, pois ela tinha todos os traços do sangue puro da família Wolf: pele branca, cabelos loiros, era aplicada nos estudos e se dedicava à arte. No entanto, essa sensação de brilho e alegria se

\footnotetext{
5 "Eu sabia que o casamento de meu pai com ela causara muita agitação na família, o desgosto naquela que todos chamavam Fraw Wolf. Otto, o filho querido, primeiro membro da família a se casar com alguém que não era de origem alemã: quando minha avó me fitava com desagrado, eu me envergonhava como se fosse mestiça". (LUFT, 2004, p. 37).

6 "Anemarie, a predileta da família, cabelo dourado caindo até os quadris quando os destrançava. A neta amada de Frau Wolf estudava num internato longe e eu raramente a via. Mas quando chegava, a vida em casa de nossa avó se transfigurava - eu acreditava que o mundo podia ser belo" (LUFT, 2004, p. 13).
} 
transformou em escuridão e ódio, pois a amada e preferida da família mantém um caso secreto com um dos seus tios, Stefan o marido de Marta, filha de Fraw Woolf e tia de Anemarie e Gisela.

A traição de Anemarie e Stefan faz com que a família Wolf se tornasse motivo de piadas e chacotas em toda a cidade. Todo o sentimento de Faru Wolf pela neta preferida fora traído e a matriarca não a perdoou, pois dez anos depois a neta regressa doente, acometida por um câncer que a leva à morte, no entanto ela não recebe o perdão da avó, pelo contrário a atuação da matriarca na cena do velório choca a todos.

\footnotetext{
Quase na hora do enterro, o ar estava sufocante na sala e as pessoas estavam espalhadas pelo jardim conversando como numa festa, Frau Wolf desceu as escadas. A grande dama: nos cantos da boca mostrava o desprezo pelo mundo. Percebi que se apoiava fortemente na bengala. Meu pai apertou minha mão, a dele estava gelada. Junto do caixão minha avó falou com voz inexpressiva, mas firme: - Abram a tampa... Minha avó contemplou a criatura que talvez mais tivesse amado na vida. A mão tremeu na bengala, os olhos desbotados não pestanejaram. Depois deu um passo atrás, e sem qualquer sinal prévio cuspiu no chão diante da caixa negra (LUFT, 2004, p. 92-93).
}

A reprovação da avó pela atitude da neta, como a doença que a consome representam a repressão social, uma espécie de castigo por ter violado as regras sociais, transgredindo os valores apregoados pela matriarca da família. A morte de Anemarie representa o início da decadência da família Wolf. Ela, que em vida, era o anjo que embelezava os encontros e festas da família, após morrer, será comparada ao anjo que guarda o jazigo da família no cemitério onde jazem todos os descendentes da família.

Para Gisela, o anjo do jazigo era "misterioso concentrado na pesada matéria em que se imobilizava a eternidade do seu gesto e expressão, os enigmas da vida e da morte" (LUFT, 2004, p. 33). Recorrendo à simbologia, os anjos representam glória, beleza e encantamento, época em que tudo saía como o esperado da matriarca. Mas, a traição de Anemarie, representa o contrário, o anjo caído, uma imagem de Lúcifer, a traição, e essa cena fica claro no momento em que Gisela percebe que o anjo que guarda o mausoléu da família começa a pender a asa esquerda.

A partir da metáfora da queda da asa do anjo, começa a queda da família Wolf. A matriarca começa a perder sua imposição na família, os costumes já não são respeitados, poucos a visitam, e participam dos almoços de domingo que outrora eram quase uma obrigação para todos os membros da família. A bengala que antes representava um instrumento de poder para Frau Wolf agora era um elemento que representa sua fraqueza e impossibilidade de locomover sem a ajuda desse utensílio. Sua derrocada final está presente na lembrança que Gisela tem de sua morte: 
Pela primeira vez vejo minha avó derreada em sua poltrona. A mão segura a bengala, não indiferente como sempre, mas como quem se agarra para não despencar. Não sentou na beirada da poltrona, caiu um pouco para o lado e para trás, como se houvesse desistido de tudo. Da pose, da farsa, do palco. Sinto pena.

Hesito um pouco antes de me aproximar, não desejo perturbar seu momento de fraqueza.

Quando chego perto, constato que Frau Ursula Wolf morreu. [...]. (LUFT, 2004, p. 103-104).

Um a um, os membros da família de Gisela foram sendo arrebatados pelo anjo. E até mesmo no amor ela não foi capaz de encontrar uma base familiar. Possuiu um relacionamento com Léo, mas esse não se realizou, pois a cena da violência sexual que ela presenciara anteriormente a fazia ficar com medo de qualquer contato com um homem ${ }^{8}$. E ela usava das mortes que acometiam os membros de sua família para protelar um possível casamento com seu amado, até que o relacionamento chegou ao fim, e ele morreu num trágico acidente de carro.

A Gisela, no fim da sua história, resta apenas a companhia de seu pai enfermo de quem ela cuida, e os afazeres da casa. Pois, embora tenha lutado ao longo de toda sua vida para não aceitar os padrões impostos por sua avó, acaba se tornando uma dona de casa, uma réplica fracassada da imagem da verdadeira Frau Wolf. Além disso, tenta expulsar um inquilino maldito de suas entranhas, um verme ${ }^{9}$ que a atormenta desde a infância, e é ao tentar expulsá-lo de seu organismo, que ela rememorou toda sua história. O que mais a aterroriza é que em vida não fora aceita pela família, e também na morte não faria parte do jazigo da família, haja vista que a última gaveta do mausoléu da família Wolf aguardava a chegada de seu pai.

Podemos perceber que ao longo de toda a trama de $A$ asa esquerda do anjo, as personagens de Lya Luft, principalmente as mulheres, foram colocadas numa espécie de jogo, mas um jogo sujo em que elas sempre foram perdedoras, pois o patriarcado imperou, fazendo com que elas não conseguissem escapar das regras impostas por ele.

\section{LAÇOS ENTRE LYGIA FAGUNDES TELLES E LYA LUFT}

\footnotetext{
7 “Talvez não casar tenha sido minha maneira de preservar o que me foi possível conhecer do amor. Tio Ernest e tia Helga: como poderia suportar aquelas humilhações? Nos filmes as pessoas sempre parecem sofrer na hora do amor. Carne quente de galinhas sendo degoladas na chácara, e eu obrigada a assistir. Virgem sangra na primeira noite, acho horrível. Porcos guinchavam nos chiqueiros, estão sendo esfaqueados ou outra coisa? Não, nem por Leo eu teria me submetido". (LUFT, 2004, p. 106-107).

8 "E ele vem. Enche minha boca, sai em borbotões, retorcemo-nos os dois, tenho medo de morrer - eu que sempre me preservei. Ele rasteja na minha língua. Fecho os olhos, não suporto a visão. O que estará saindo de mim? [...]. não tive um filho com Leo, não abri minhas pernas, mas pari esta criatura que, enrodilhada, bebe o leite que lhe ofereci". (LUFT, 2004, p. 108-109).
} 
Ao analisarmos a produção das duas autoras, percebemos o quanto a temática da família se torna instigante nas obras delas. Personagens que se assemelham por não se sentirem pertencentes às famílias das quais descendem. Gisela é filha de um alemão e uma brasileira, uma mulher negra e nordestina o que desagrada a matriarca da família. Ana Luisa também é filha de um alemão, mas sua mãe é judia, isso contribui para os mascaramentos que sua avó usa para esconder da personagem a sua real descendência.

Em ambas as narrativas, a memória aparece como uma estratégia de composição, não apenas como um elemento qualquer. Ao utilizar desse recurso, as autoras demonstram o quanto é difícil e dolorido estar no mundo, pois todas as personagens estabelecem suas relações conflituosas com lembranças do passado, numa tentativa de lembrar e esquecer (LUCENA, 2013). Gisela busca rememorar todos os passos dela e da família na tentativa de entender o porquê de não ser aceita pelos membros familiares da família Wolf, como também quando aquele monstro que agora está prestes a expulsar de seu corpo se alojou nela. Ana Luisa busca, de certa forma, esquecer suas raízes, sua descendência de uma judia, haja vista que sua avó, uma nazista, aprovava as perseguições de Hitler, elogiando-o como um homem de verdade. Essas lembranças que Ana Luisa, fracassadamente, tenta esquecer é o que gera todos os conflitos da narrativa.

Tanto a narradora personagem de Lya Luft quanto a de Lygia Fagundes Telles são frutos de família degradas, onde a traição, o ódio, a hipocrisia e a opressão se fazem presentes na imagem das matriarcas da família. Pois, em ambas as narrativas as personagens masculinas pouco aparecem, na verdade já estão mortos e são citados apenas através de lembranças do passado. Porém, como nos afirma Lucena (2015), não podemos nos deixar seduzir e enganar pela descrição de homens mortos ou enfraquecidos, pois mesmo sendo descritos como homens fracos e apáticos tratam-se de descrições que reforçam a ideia do fracasso familiar devido à ausência e/ou morte do pai, sendo que quando isso ocorre desencadeia crises e desajustes familiares de todo tipo.

A análise interpretativa dos textos ficcionais abordados, nesse ensaio, mostra-nos o quanto Lygia Fagundes Telles e Lya Luft desnudam para nós os enfrentamentos familiares brutais, secretos ou abertos, a memória enquanto castigo para as personagens que, como numa espécie de jogo entre tempo, destino e morte são encurraladas em ambientes sufocantes e muita solidão. Podemos afirmar que os textos analisados representam, em grande estilo, "o tumulto das emoções, a crueldade da vida, a morbidez de certos ambientes e o lirismo do sonho - nós, desnudados, fortes e frágeis, líricos e cruéis, e tão intrigantes” (LUFT, 2014, s/p) ${ }^{10}$.

\footnotetext{
${ }^{9} \mathrm{~A}$ referida citação se encontra sem página, porque faz parte da orelha do livro intitulada Nélida, sombra e sedução, escrita por Lya Luft, para o livro A camisa do marido, de Nélida Piñon. O referido livro também apresenta histórias que giram em torno dos dramas familiares.
} 


\section{REFERÊNCIAS}

BACHELARD, Gaston. A poética do espaço. São Paulo: Martins Fontes, 1989.

BEAUVOIR, Simone de. O segundo sexo: a experiência vivida, volume 2; trad. Sérgio Milliet. 3. Ed. Rio de Janeiro: Nova Fronteira, 2016.

BULNFINCH, Thomas. O livro de ouro da mitologia: história de deuses e heróis. Rio de Janeiro: Ediouro, 2006.

CAMARGO, Luciana Moura Colucci de; FILHO, Ozíris Borges. Espaço e identidade em verde lagarto amarelo. In: MAGNO, Carlos; LUCENA, Suênio Campos de. (orgs.). Lygia Fagundes Telles entre ritos e memórias. Aracaju: Editora Criação; Itabaiana: UFS, 2013.

CARDOSO, Fabiano. A construção da identidade feminina em A esquerda do anjo, de Lya Luft. In: VI Encontro de Produção Científica e Tecnológica. Disponível em: http://www.fecilcam.br/nupem/anais vi epct/PDF/linguistica letras artes/02.pdf $>$ acesso em 03 de março de 2017, às 08h39min.

CHEVALIER, Jean; GHEERBRANT, Alain. Dicionário de simbolos: (mitos, sonhos, costumes, gestos, formas, figuras, cores, números). Rio de Janeiro: José Olympio, 2012.

GENS, Rosa Maria de Carvalho. A infância em contos de Lygia Fagundes Telles. In: Cadernos da FaEL. V. 1. No 3. (Set./Dez, 2008).

LUCENA, Suênio Campos de. Lygia Fagundes Telles. In: Blecaute - uma revista de literatura e artes. Campina Grande. Ano 5. No 114 - março 2013. (p. 31 -37).

Para a família que eu não salvei: o fracasso familiar na obra de Lygia Fagundes Telles. Ensaio de pós-doutoramento em Teoria Literária e Literatura Comparada, da Faculdade de Filosofia, Letras e Ciências Humanas, da Universidade de São Paulo. Julho de 2015.

Sobre lembrar e esquecer nos romances e contos. In: MAGNO, Carlos e LUCENA, Suênio Campos de. (orgs.). Lygia Fagundes Telles entre ritos e memórias. Aracaju: Criação. Itabaiana: UFS, 2013.

LUFT, Lya. A asa esquerda do anjo. 12. Ed. - Rio de Janeiro: Record, 2004.

Record, 2014.

Nélida, sombra e sedução. In: PIÑON, Nélida. A camisa do marido. Rio de Janeiro:

TELLES, Lygia Fagundes. O espartilho. In: $A$ estrutura da bolha de sabão. São Paulo: Companhia das Letras, 2010.

XAVIER, Elódia. Narrativa de autoria feminina na literatura brasileira. Disponível em: http://litcult.net/narrativa-de-autoria-feminina-na-literatura-brasileira-as-marcas-da-trajetoria/> acesso em 06 de março de 2017, às 19h39min. 